\title{
Improvements in French risk stratification score were correlated with reductions in mean pulmonary artery pressure in pulmonary arterial hypertension: a subanalysis of the Japan Pulmonary Hypertension Registry (JAPHR)
}

Yuichi Tamura ${ }^{1 *}$, Hiraku Kumamaru ${ }^{2}$, Kohtaro Abe $^{3}$, Toru Satoh ${ }^{4}$, Hiroaki Miyata ${ }^{2,5}$, Aiko Ogawa $^{6}$, Nobuhiro Tanabe ${ }^{7}$, Masaru Hatano ${ }^{8}$, Atsushi Yao ${ }^{9}$, Ichizo Tsujino ${ }^{10}$, Keiichi Fukuda ${ }^{11}$, Hiroshi Kimura ${ }^{12}$, Masataka Kuwana ${ }^{13}$, Hiromi Matsubara ${ }^{6}$ and Koichiro Tatsumi ${ }^{14}$ on behalf of the Japan Pulmonary Hypertension Registry (JAPHR) Network

\begin{abstract}
Background: Since there was no previous report, we analyzed the relationship between French Risk Stratification parameters in pulmonary arterial hypertension (PAH) and mean pulmonary arterial pressures (mPAP) using Japan $\mathrm{PH}$ Registry (JAPHR) national-wide cohort.

Methods: We enrolled 108 patients with PAH from JAPHR from previous reported cohort and analyzed the relations between French Risk Stratification scores and hemodynamic improvements.

Results: The ratio meeting 0 to 4 French Risk Stratification score was $21.3 \%, 31.5 \%, 32.4 \%, 13.0 \%$, and $1.9 \%$ at baseline, and $6.5 \%, 23.2 \%, 33.3 \%, 23.2 \%, 13.9 \%$ at follow-up, respectively. The improvements in the number of criteria met were associated both with mPAP at follow-up $(p=0.03)$ and with the improvements in mPAP $(p<0.001)$.
\end{abstract}

Conclusion: The improvements in French Risk Stratification may become a marker of improved hemodynamics including mPAP.

Keywords: Pulmonary arterial hypertension, Registry, Risk stratification, Mean pulmonary arterial pressures

\section{Background}

In the ESC/ERS pulmonary hypertension $(\mathrm{PH})$ guidelines, right atrial pressure (RAP) and cardiac index (CI) have been proposed as hemodynamic parameters for pulmonary arterial hypertension (PAH) risk stratification [1]. Before the advent of current pulmonary vasodilators,

\footnotetext{
*Correspondence: u1@ta-mu.net

1 Pulmonary Hypertension Center, International University of Health and Welfare Mita Hospital, Tokyo, Japan

Full list of author information is available at the end of the article
}

as $\mathrm{PAH}$ progresses and the right ventricle dilates and fails, the mean pulmonary arterial pressure (mPAP) declines, resulting in the poor survival of patients with $\mathrm{PAH}$. Therefore, past guidelines for $\mathrm{PAH}$ treatment recommended normalization of right ventricular function as a treatment goal, which is defined as $\mathrm{RAP}<8 \mathrm{mmHg}$ and $\mathrm{CI}>2.5 \mathrm{~L} / \mathrm{min} / \mathrm{m}^{2}$. As a result, $\mathrm{mPAP}$ has been excluded as not only as a therapeutic target but also as a risk stratification marker. Recently, the French registry group proposed the French Risk Stratification for PAH, which includes RAP and $\mathrm{CI}$ as risk stratification markers at the 
time of diagnosis and during treatment [2]. The reliability of these risk stratification parameters has been supported in multiple conditions and registries [3]. However, with the progress of therapeutic strategies, including combination therapy, recent clinical observations suggest the possibility that mPAP may be an independent treatment goal. Ogawa et al. [4] reported that the survival rate of patients with $\mathrm{mPAP} \leq 46 \mathrm{mmHg}$ at follow-up was significantly better than that of patients with $\mathrm{mPAP}>46 \mathrm{mmHg}$ in 141 patients with idiopathic/heritable $\mathrm{PAH}$ at $3 \mathrm{PH}$ centers in Japan. Thus, we expected that the current treatment strategy of using combination therapy improves not only the CI but also mPAP during follow-up in patients with PAH.

In this study, we aimed to analyze the changes in French Risk Stratification parameters and mPAP from baseline to the follow-up period using the Japan PH Registry (JAPHR) nationwide cohort.

\section{Methods}

Patients registered in the JAPHR before 2013 and who initiated PH-specific treatment in or before March 2013 were included in the study. We extracted patients' clinical information on WHO FC / NYHA classification, 6-min walking distance (6MWD), RAP, CI, and MPAP at baseline and at the first follow-up visit which was already reported [5]. We then categorized patients based on the number of risk stratification criteria that each patient met: i.e., NYHA classification $\mathrm{I} / \mathrm{II}, 6 \mathrm{MWD}>440 \mathrm{~m}$, $\mathrm{RAP}<8 \mathrm{mmHg}$, and $\mathrm{CI}>2.5 \mathrm{~L} / \mathrm{m}^{2}$, both at baseline and at the first follow-up. We also categorized patients into 3 groups based on the change in the number of criteria met between baseline and follow-up: improved (number of factors increased), unchanged (number of factors unchanged) and worsened (number of factors reduced). We compared the distribution of mPAP across these different risk groups using a Kruskal-Wallis test. Tests were all two-sided and p-values $<0.05$ were considered statistically significant. This study was approved by the ethics committee of International University of Health and Welfare (Approval \#5-19-11), and followed the Declaration of Helsinki and the ethical standards of the responsible committee on human experimentation. All patients provided written informed consent to participate.

\section{Results}

We identified 108 patients matching the inclusion criteria in the database. The number of patients meeting each of the risk stratification criterion at baseline were 37 (34.3\%), 10 (9\%), $72(67 \%)$, and 35 (33\%) for NYHA I/ II, $6 \mathrm{MWD}>440 \mathrm{~m}, \mathrm{RAP}<8 \mathrm{mmHg}$, and $\mathrm{CI} \geq 2.5 \mathrm{~L} / \mathrm{min} /$ $\mathrm{m}^{2}$, respectively. At the first follow-up, the corresponding values were 59 (54.6\%), 25 (23.2\%), 84 (77.8\%), and 64
(59.3\%). The number of patients meeting 0 to 4 criteria was 23 (21.3\%), 34 (31.5\%), 35 (32.4\%), 14 (13.0\%), and 2 (1.9\%) at baseline, and 7 (6.5\%), 25 (23.2\%), 36 (33.3\%), $25(23.2 \%), 15$ (13.9\%) for 0 to 4 at follow-up, respectively (Fig. 1). The median mPAP at the first follow-up decreased with the increase in criteria met: $44.0 \mathrm{mmHg}$ for $0,41.0 \mathrm{mmHg}$ for $1,37.0 \mathrm{mmHg}$ for $2,35.0 \mathrm{mmHg}$ for 3 , and $32.5 \mathrm{mmHg}$ for 4 ( $p=0.03$, Fig. 2). Categorizing the patients into groups based on the change in the number of criteria met revealed that 58 (53.7\%) improved, 30 (27.8\%) were unchanged, and 10 (9.3\%) worsened (Fig. 1). This grouping was associated with both MPAP at followup $(p=0.03)$ and the improvement in the mPAP at follow-up from baseline ( $p<0.001$, Fig. 3$)$.

\section{Discussion}

The evaluation of French risk stratification at baseline and follow-up in the JAPHR cohort revealed that the risk stratification score correlated with MPAP at follow-up. It was also found that improvements in the risk stratification score correlated with those in mPAP.

The most important point in this study is that improvement in the risk stratification score and hemodynamic parameters are closely related, especially in MPAP, in the JAPHR cohort. NIH registry data [6] indicated that not only increased RAP and decreased CI but also increased mPAP were associated with increased mortality in patients with primary $\mathrm{PH}$. However, until now, most randomized controlled trials found mPAP improvement to be a poor prognosis factor [7]. One possible reason is that multiple monotherapy studies only showed minor improvements in mPAP, meaning that monotherapy itself has less capacity to improve mPAP. However, a report of triple combination therapy suggests that combination therapy including epoprostenol may improve not only the CI but also mPAP [8]. In addition, a JAPHR study reported that $85 \%$ of patients on upfront combination therapy had $a \geq 20 \%$ reduction in mPAP at the follow-up period, resulting in beneficial outcomes [5]. Therefore, in treatment with combination therapy, it is expected that lowering the risk stratification score will lead to a hemodynamic improvement in pulmonary circulation associated with not only right ventricular function but also mPAP. Regarding a novel treatment algorithm targeting risk stratification proposed in Nice 2018 [3], the results of the present study suggest that this algorithm improves not only risk stratification scores but also mPAP.

This study has some limitations. First, this cohort has data from advanced PH centers in Japan; as previously reported, the mortality and lung transplant events were less frequent and the prognosis was better than those of existing reports [5]. Therefore, it was difficult to verify any correlations between risk stratification 

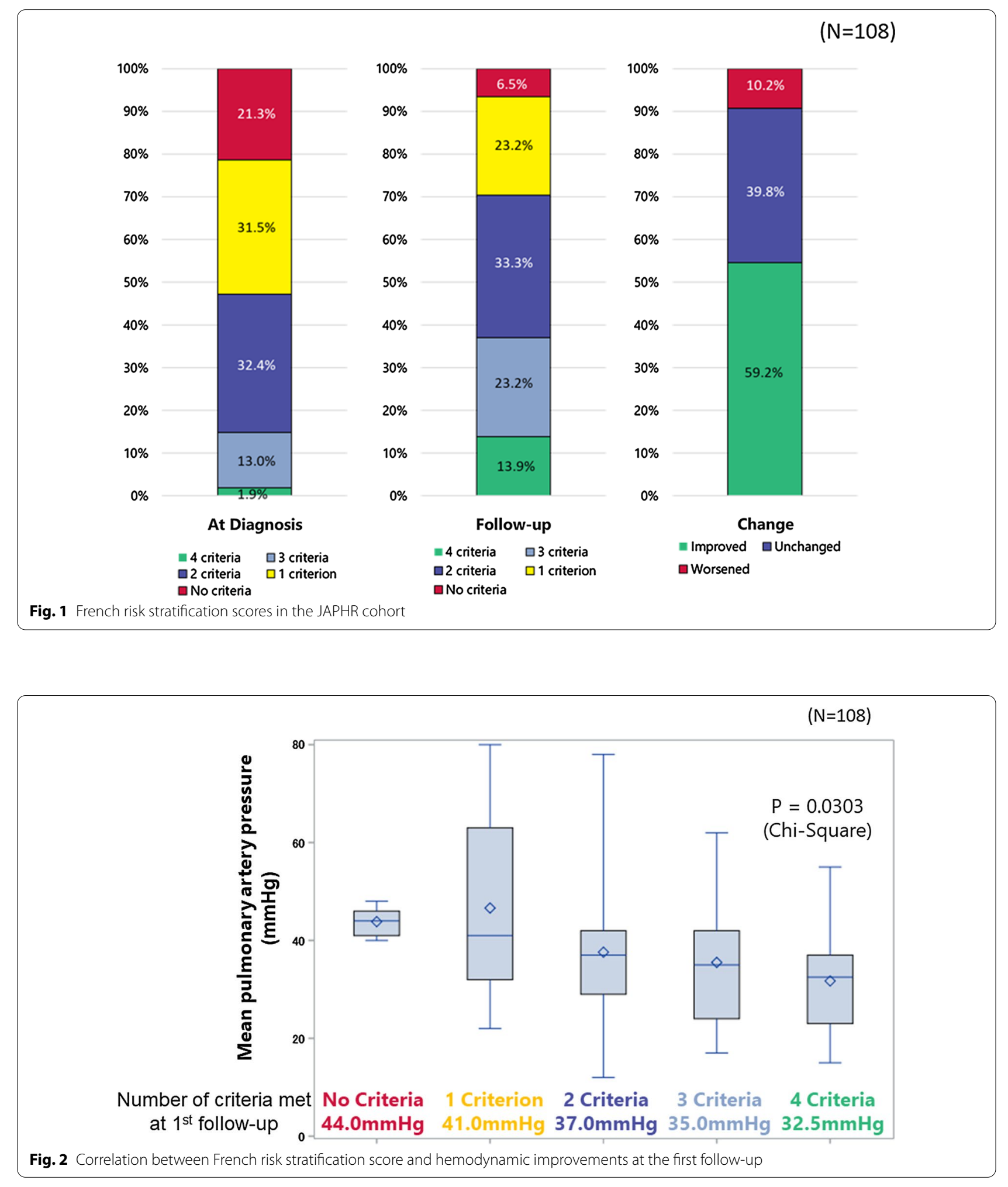

score and prognosis at the initial visit or follow-up, as reported previously in other studies. However, absolute improvements in hemodynamics, as well as in right heart failure and symptoms contained in the risk stratification score, may indicate that patients in this cohort had a better prognosis. Second, a decrease in mPAP 


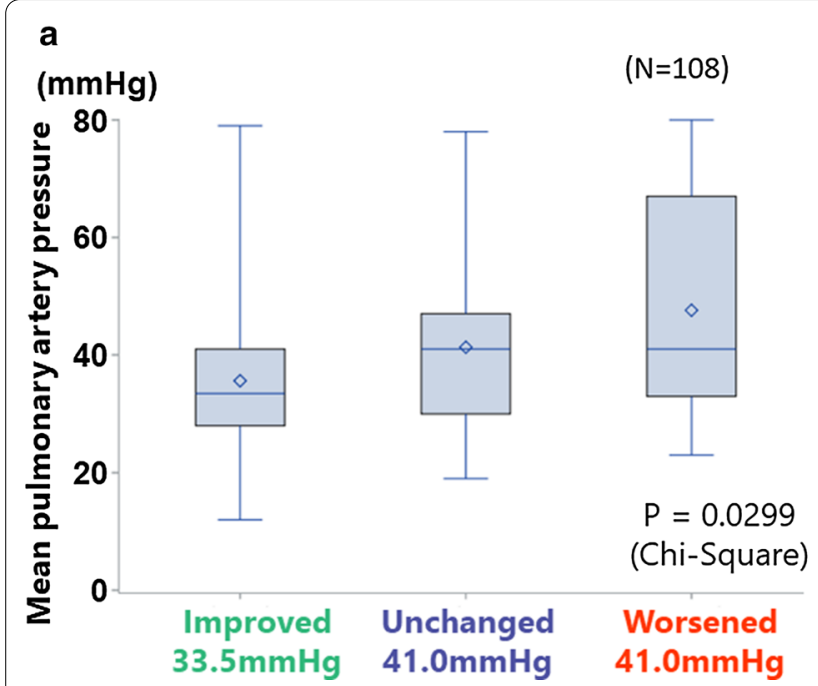

b

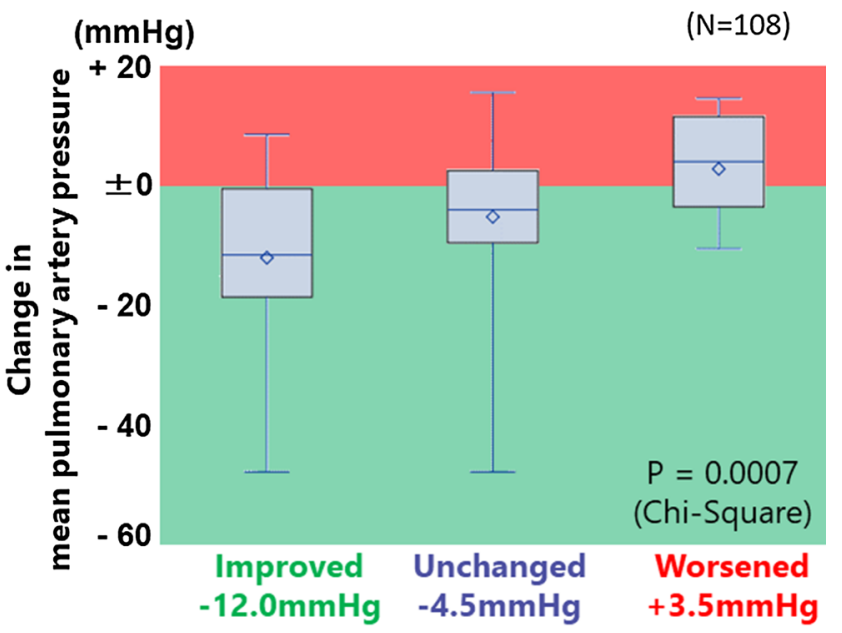

Fig. 3 Relationship between the improvements in French risk stratification score and mean pulmonary artery pressure. a mean pulmonary artery pressures in the 3 groups of patients according to the improvement in French risk stratification score. $\mathbf{b}$ changes of mean pulmonary artery pressures on 3 groups of patients according to the improvement in French risk stratification score

sometimes originate from worsening heart failure or decreases in cardiac output. However, since the risk stratification score includes indices such as $\mathrm{CI}$ and RAP, it is not expected that the decrease in mPAP was due to the progression in cardiac dysfunction. Moreover, only rare cases suffered from decreased mPAP associated with cardiac output impairment in our cohort because this cohort had better prognosis concomitant with hemodynamic improvements [5]. Third, this study was conducted in the cohort up to 2013, and the number of cases was small compared to the original French report [2]. However, compared with the French cohort, the distribution of patients in each risk score after the initial treatment did not differ, which validates the risk score in Japanese patients. Therefore, this study may contribute to the future universalization of evaluation methods for therapeutic interventions.

\section{Conclusion}

In conclusion, the assessment of risk stratification score improvements, may become a novel marker of improved hemodynamics, including mPAP, in JAPHR.

\section{Abbreviations}

PH: Pulmonary hypertension; RAP: Right atrial pressure; Cl: Cardiac index; PAH: Pulmonary arterial hypertension; mPAP: Mean pulmonary arterial pressure; JAPHR: Japan pulmonary hypertension registry; WHO FC: World Health Organization functional classification; NYHA: New York Heart Association; 6MWD: 6-Min walking distance; NIH: National Institutes of Health.

\section{Acknowledgements}

Not Applicable

\section{Authors' contributions}

YT: study manager and wrote the manuscript; $H K$ and HM1: performed statistical analysis as statisticians, KA, TS, AO, NT, MH, AY, IT, KF, HK, MK and HM2: gathered clinical data; KT: interpretation of data. All authors have read and approved the final version of this manuscript.

\section{Funding}

This research was supported by a Health Labor Sciences Research Grant, Japan and AMED under Grant Number JP18lk1601003h0001. The role of these funding body was the design of the study and collection of data.

\section{Ethics approval and consent to participate}

This study was approved by the ethics committee of International University of Health and Welfare (Approval \#5-19-11), and followed the Declaration of Helsinki and the ethical standards of the responsible committee on human experimentation. All patients provided written informed consent to participate. To access the raw data for this study, the steering committee of Japan PH Registry gave a permission to the statisticians.

\section{Consent for publication}

Written informed consent for publication of their clinical details was obtained from all of the patients. A copy of the consent form is available for review by the Editor of the journal.

\section{Availability of data and materials}

All clinical data were obtained from medical records in each active centers. 11The data that support the findings of this study are available from Japan PH Registry (nonprofit organization) but restrictions apply to the availability of these data, which were used under license for the current study, and so are not publicly available. Data are however available from the authors upon reasonable request and with permission of Japan PH Registry.

\section{Competing interests}

Dr. Yuichi Tamura received a research grants from Bayer Yakuhin, Nippon Shinyaku Pharma, and Actelion pharmaceuticals Japan.

\section{Author details}

${ }^{1}$ Pulmonary Hypertension Center, International University of Health and Welfare Mita Hospital, Tokyo, Japan. ${ }^{2}$ Department of Healthcare Quality Assessment, Graduate School of Medicine, The University of Tokyo, Tokyo, Japan. ${ }^{3}$ Department of Cardiovascular Medicine, Kyushu University Hospital, 
Fukuoka, Japan. ${ }^{4}$ Department of Cardiology, Kyorin University School of Medicine, Mitaka, Japan. ${ }^{5}$ Department of Health Policy and Management, Keio University School of Medicine, Tokyo, Japan. ${ }^{6}$ Department of Clinical Science, National Hospital Organization Okayama Medical Center, Okayama, Japan. ${ }^{7}$ Pulmonary Hypertension Center, Chibaken Saiseikai Narashino Hospital, Narashino, Japan. ${ }^{8}$ Department of Cardiovascular Medicine, The University of Tokyo Hospital, Tokyo, Japan. ${ }^{9}$ Division for Health Service Promotion, The University of Tokyo, Tokyo, Japan. ${ }^{10}$ First Department of Medicine, Hokkaido University Hospital, Sapporo, Japan. ${ }^{11}$ Department of Cardiology, Keio University School of Medicine, Tokyo, Japan. ${ }^{12}$ Department of Pulmonary Medicine, Nippon Medical School Graduate School of Medicine, Tokyo, Japan. ${ }^{13}$ Department of Allergy and Rheumatology, Nippon Medical School Graduate School of Medicine, Tokyo, Japan. ${ }^{14}$ Department of Respirology, Graduate School of Medicine, Chiba University, Chiba, Japan.

Received: 2 May 2020 Accepted: 4 January 2021

Published online: 14 January 2021

\section{References}

1. Galie N, Humbert M, Vachiery JL, Gibbs S, Lang I, Torbicki A, et al. 2015 ESC/ERS Guidelines for the diagnosis and treatment of pulmonary hypertension: the Joint Task Force for the Diagnosis and Treatment of Pulmonary Hypertension of the European Society of Cardiology (ESC) and the European Respiratory Society (ERS): Endorsed by: Association for European Paediatric and Congenital Cardiology (AEPC), International Society for Heart and Lung Transplantation (ISHLT). Eur Respir J. 2015;46:903-75. https://doi.org/10.1183/13993003.01032-2015.
2. Boucly A, Weatherald J, Savale L, Jaïs X, Cottin V, Prevot G, et al. Risk assessment, prognosis and guideline implementation in pulmonary arterial hypertension. Eur Respir J. 2017. https://doi.org/10.1183/13993 003.00889-2017.

3. Galie N, Channick RN, Frantz RP, Grünig E, Jing ZC, Moiseeva O, et al. Risk stratification and medical therapy of pulmonary arterial hypertension. Eur Respir J. 2019. https://doi.org/10.1183/13993003.01889-2018.

4. Ogawa A, Satoh T, Tamura Y, Fukuda K, Matsubara H. Survival of Japanese patients with idiopathic/heritable pulmonary arterial hypertension. Am J Cardiol. 2017;119:1479-84. https://doi.org/10.1016/j.amjcard.2017.01.015.

5. Tamura Y, Kumamaru H, Satoh T, Miyata H, Ogawa A, Tanabe N, et al. Effectiveness and outcome of pulmonary arterial hypertension-specific therapy in Japanese patients with pulmonary arterial hypertension. Circ J. 2017;82:275-82. https://doi.org/10.1253/circj.CJ-17-0139.

6. D'Alonzo GE, Barst RJ, Ayres SM, Bergofsky EH, Brundage BH, Detre KM, et al. Survival in patients with primary pulmonary hypertension Results from a national prospective registry. Ann Intern Med. 1991;115:343-9.

7. Galiè N, Manes A, Negro L, Palazzini M, Bacchi-Reggiani ML, Branzi A. A meta-analysis of randomized controlled trials in pulmonary arterial hypertension. Eur Heart J. 2009;30:394-403.

8. Sitbon O, Jaïs X, Savale L, Cottin V, Bergot E, Macari EA, et al. Upfront triple combination therapy in pulmonary arterial hypertension: a pilot study. Eur Respir J. 2014;43:1691-7. https://doi.org/10.1183/09031936.00116 313.

\section{Publisher's Note}

Springer Nature remains neutral with regard to jurisdictional claims in published maps and institutional affiliations.
Ready to submit your research? Choose BMC and benefit from:

- fast, convenient online submission

- thorough peer review by experienced researchers in your field

- rapid publication on acceptance

- support for research data, including large and complex data types

- gold Open Access which fosters wider collaboration and increased citations

- maximum visibility for your research: over 100M website views per year

At BMC, research is always in progress.

Learn more biomedcentral.com/submissions 